\title{
NEW LEVEL 2 AUTOMATION SYSTEMS FOR JSW STEEL TORANAGALLU*
}

\author{
Rudolf Hubmer ${ }^{1}$ \\ Josef Weiss ${ }^{2}$ \\ N. Desai
}

\begin{abstract}
In October 2013 JSW Steel decided to place an order to Primetals Technologies Austria (former Siemens VAI Metals Technologies) for the installation of a comprehensive Level 2 process optimization system for more than 20 existing production facilities of various suppliers. For SMS-I new L2 systems are provided for two hot metal pretreatment stations, three hot metal desulphurization stations, three ladle furnaces, two 1-strand slab casters, a ladle tracking system as well as a shop supervisory system. Additionally the existing L2 system for one 1-strand slab caster is being upgraded in the course of the project. In SMS-II new L2 systems for the 7 hot metal desulphurization stations, 4 ladle furnaces, 1 new $\mathrm{RH}$ vacuum degasser, ladle tracking system and a shop supervisory system are supplied. Despite of the challenging time schedule the commissioning of the single facilities started within less than 12 month after contract effectiveness. The installed Level 2 process optimization systems together with the achieved results are described in this paper.

Keywords: Steel plant automation; Primetals Technologies; Process optimization; JSW steel plant; Level 2 automation.
\end{abstract}




\section{INTRODUCTION}

The JSW Steel Ltd has become India's largest private sector steel company with an installed capacity of 14.3 MTPA. The JSW Steel Vijayanagar plant in Toranagallu is the first integrated steel plant in India to reach 10 MTPA capacity in a single location. In October 2013 JSW Steel decided to place an order to Primetals Technologies for the installation of a comprehensive Level 2 process optimization system for 25 existing production facilities of various suppliers. For SMS-I new L2 systems are provided for two twin hot metal pretreatment stations, three hot metal desulphurization stations, three ladle furnaces, four 1-strand slab casters, a ladle tracking system as well as a shop supervisory system. Additionally the existing L2 system for one 1-strand slab caster is being upgraded in the course of the project. In SMS-II new L2 systems for the 7 hot metal desulphurization stations, 4 ladle furnaces, 1 new $\mathrm{RH}$ vacuum degasser, ladle tracking system and a shop supervisory system are supplied.

Following the challenging time frame from JSW Steel Ltd the factory acceptance test has been passed in July 2014 and the commissioning of the single facilities started within less than 12 month after contract effectiveness.

\section{INTEGRATED STEEL PLANTS AT JSW VIJAYANAGAR}

The JSW Group's step into steel manufacturing began in 1982, when it set up the Jindal Iron and Steel Company with its first steel plant at Vasind near Mumbai. The next two decades saw significant expansion and several acquisitions.

Today JSW Steel has plants in six locations in India. The global operations include a plate and pipe mill in the US. Today, with an installed capacity of 14.3 MTPA, JSW Steel is India's leading private sector steel producer and among the world's most illustrious steel companies.

\section{CONFIGURATION OF STEEL MELTSHOPS SMS-I AND SMS-II}

The steel plant consists of two steel meltshops, called SMS-I and SMS-II. The hot metal is produced in 4 blast furnaces and 2 COREX plants Module C-2000 and transported via torpedo ladles to the steel meltshops. The individual plant units of each meltshop are listed in Figure 1 below.

\begin{tabular}{|lll|}
\hline Plant Area & $\begin{array}{l}\text { SMS-I } \\
\text { meltshop }\end{array}$ & SMS-II meltshop \\
\hline Hot Metal & $\begin{array}{l}2 \times 2 \text { HMPT, } 3 \\
\text { x HMDS }\end{array}$ & $7 \times$ HMDS \\
& $3 \times 135$ t BOF & $4 \times 175$ t BOF \\
\hline Primary Metallurgy & $3 \times$ LF, 1 $\times$ RH & $4 \times$ LF, 2 $\times$ RH \\
\hline Secondary Metallurgy & $4 \times 1$-strand & $3 \times 1$-strand slab caster \\
\hline Casting & slab caster & $1 \times 8$-strand billet caster \\
& & $1 \times 1$-strand slab caster \\
& & under erection \\
\hline
\end{tabular}

Figure 1. Plant units of SMS-I and SMS-II

\section{PROJECT CONFIGURATION}

The Level 2 upgrade project includes the entire Hot Metal treatment area of both meltshops, the three (3) ladle furnaces and four (4) continuos casting machines at meltshop \#1 as well as the four (4) ladle furnaces at meltshop \#2. Furthermore a 
shop supervisory system and a ladle tracking system covering all areas of both meltshops have been implemented.

New Level 2 automation systems are supplied by Primetals Technologies in total for 25 plant units. 2 plant units (SMS1 CC3 \& CC4) have been upgraded to have the same Level 2 automation system on all SMS-I continuous casting machines.

The scope of the project included not only the engineering, design, training and commissioning of the Level 2 automation systems including hardware, system software and application software for the above mentioned plant units, but also the installation of proper metallurgical process models for optimization of the production process and Level 1 modification. Additionally a Level 2 network for communication with all involved automation systems, especially the respective Level 1 systems, has been installed.

The use of the Primetals Technologies Level 2 automation system allows to react flexibly and fast on changing input materials and to stabilize the production process, The operator is guided through the different steps of production to ensure a consistent and reproducible production.

\section{HARDWARE AND NETWORK CONFIGURATION}

According to the contract a lot of hardware and networking equipment have been installed in both meltshops.

\subsection{Meltshop SMS-I}

For meltshop SMS-I the following main hardware equipment was delivered and installed: $17 \mathrm{x}$ application servers; $3 \mathrm{x}$ database servers; $2 \mathrm{x}$ external disk arrays; 39 $x$ client stations, incl. metallurgist and development stations; $8 \mathrm{x}$ laser printers; $12 \mathrm{x}$ 15 " color LCD touch screen crane terminals; 2 x large scale displays (60" colour LCD, $1920 \times 1080$ pixel).

The installed network equipment comprised of the following main equipment: $3 x$ Layer-3 Ethernet managed switches; 26 x Layer-2 Ethernet managed switches; $34 \mathrm{x}$ SFP Optical transceiver modules; $2 \times$ Hardware firewalls; $5 \times$ WiFi master access points incl. repeater; $10 \times$ WiFi client receivers; Appr. $10 \mathrm{~km}$ of fibre optic network cable; 6 x drums of Cat- 6 UTP cables.

\subsection{Meltshop SMS-II}

For meltshop SMS-II the following main hardware equipment was delivered and installed: $14 \mathrm{x}$ application servers; $3 \mathrm{x}$ database servers; $2 \mathrm{x}$ external disk arrays; 51 $x$ client stations, incl. metallurgist and development stations; $10 \mathrm{x}$ laser printers; $14 \mathrm{x}$ 15 " color LCD touch screen crane terminals; 2 x large scale displays (60" colour LCD, $1920 \times 1080$ pixel).

The installed network equipment comprised of the following main equipment: $3 x$ Layer-3 Ethernet managed switches; 36 x Layer-2 Ethernet managed switches; $41 \mathrm{x}$ SFP Optical transceiver modules; $2 \times$ Hardware firewalls; $5 \times$ WiFi master access points incl. repeater; $11 \times$ WiFi client receivers; Appr. $10 \mathrm{~km}$ of fibre optic network cable; 7 x drums of Cat- 6 UTP cables.

As an example the layout of the new installed SMS-II network is displayed in the following Figure 2. 


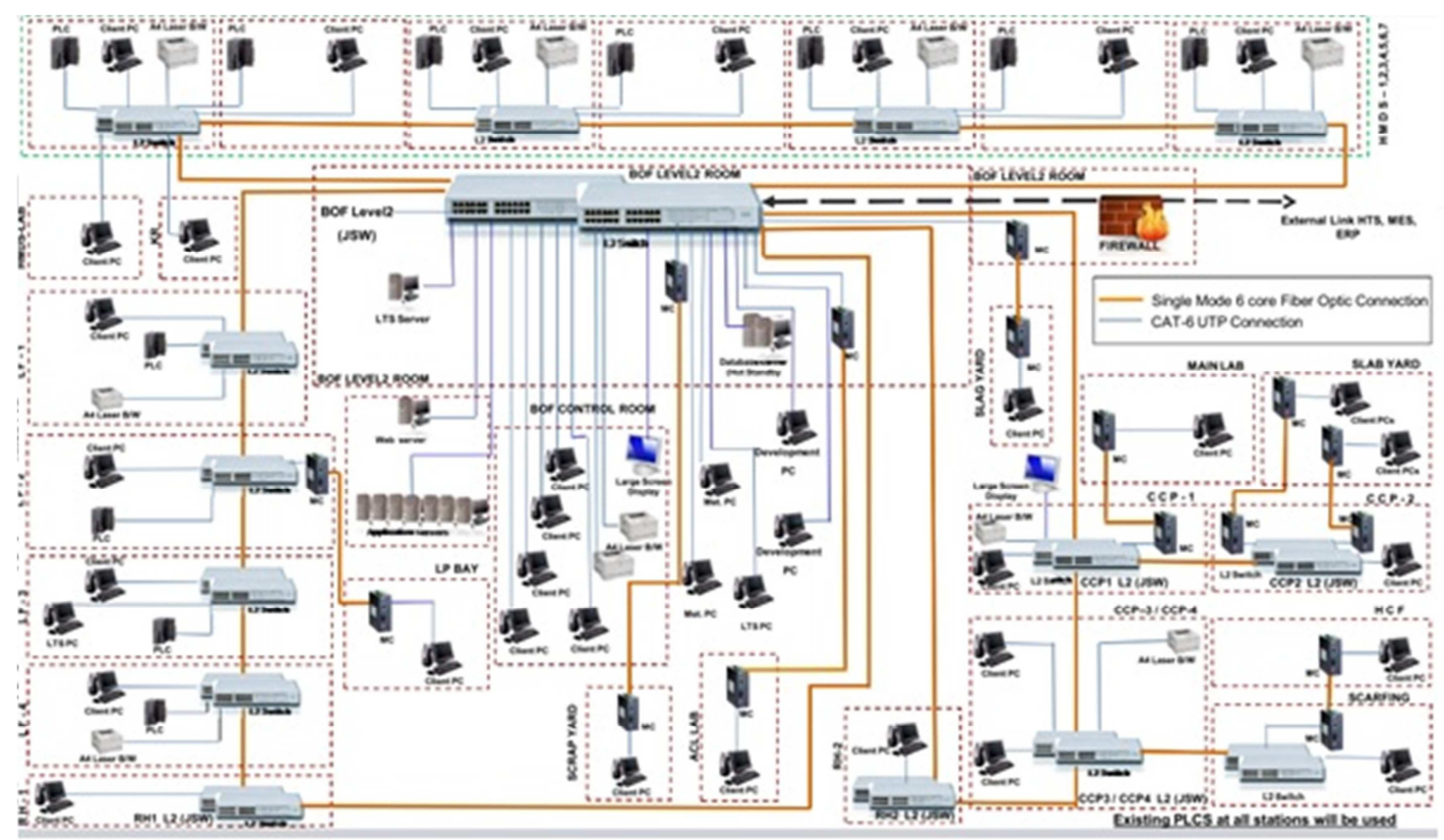

Figure 2. Installed network layout of SMS-II

\subsection{System Software}

The same standard for system software has been applied in both meltshops.

The melt shop database servers are implemented as hot standby system via Oracle Real Application Cluster technology, using an external disk array.

The Level 2 system is based on the main system software Microsoft Windows 2008 Server, MS Visual Studio .Net 2012 and Oracle $11 \mathrm{~g}$ database.

Different Level 1 interfaces to existing PLC systems from Rockwell, Schneider and Siemens have been realized.

\section{PROCESS OPTIMIZATION FUNCTIONS}

All Level 2 automation systems have the same basic concept. Beside the plant unit specific process model packages, the following functionalities are implemented:

- Plan data handling

- Process tracking

- Communication to existing automation systems

- Master data maintenance

- Reporting

Production planning and scheduling is performed by a high level production planning system. Whenever new planning information is available the data are sent to L2 via the JSW HTS system. On the other hand, production and status information is sent to L3 to enable proper updating of the overall production schedule.

Emergency dialogs are included so that the operator can manually enter information about heats to be produced.

\subsection{Process data tracking}

Process data tracking forms the core functionality of the system and provides tracking and storage of all gathered process data at the different plant units. Automatic data forwarding is properly implemented for all plant units. 


\subsection{Communication to existing automation systems}

The level 2 system of each plant unit has several communication partners, as laboratory, other Level 2 systems, Level 3 and different Level 1 systems.

\subsection{Master data maintenance}

Steel grades are basic input parameters for the level 2 system. Each order / heat is produced to meet a dedicated steel grade specification, which determines the end product. For the different plant unit additional data are needed (e.g. end of treatment analysis). Depending on actual production different aims may be adequate. To cope with such situations, treatment schemes are introduced. For instance, in Hot Metal Pre-Treatment injection schemes, oxygen blowing patterns and material addition patterns can be defined. These practices are maintained for each steel plant on a central place and deployed to the individual production units.

\subsection{Reporting}

Reports are developed by standard reporting tools (e.g.: MS-Excel). The finished report is stored as Excel file with all the data in it. Therefore the report data can easily be used for data evaluation later on. Additionally the reports are available as PDF for archiving.

\section{HOT METAL PRE-TREATMENT (HMPT)}

New Level 2 systems are implemented at the two (2) HMPT stations (each with 2 treatment positions) in SMS-I meltshop. The HM pre-treatment station itself includes an injection device for desulphurisation agents, O2-lance, material bins and a sampling lance for temperature and steel samples.

There are three different possible treatment procedures at the HMPT: DeSiliconisation (DESI), De-Phosphorisation (DEP) and De-Sulphurisation (DES).

From the user point of view there are two different process models, supporting the HMPT treatments:

- Precalculation Model: Calculation of oxygen volume, material amounts and process step durations based on hot metal analysis, hot metal temperature, treatment schemes and aim analysis ( $\mathrm{Si}, \mathrm{P}, \mathrm{S})$ at the end of the treatment. The calculated material and gas setpoints can subsequently be sent to Level 1.

- Online Model: Cyclic calculation of analysis, weight and temperature of hot metal and slag based on the actual online process data (injected materials, material additions, blown oxygen) received from Level 1. No calculation of materials is performed.

\section{HOT METAL DESULPHURISATION}

There are three (3) HMDS stations in SMS-I meltshop and seven (7) HMDS stations in SMS-II meltshop. Similar to the HMPT there is a precalculation and an online model installed.

The Precalculation Model performs a simulation of the complete heat and determines the injection rates and the amount of desulphurisation materials (Carbide, 
magnesium, lime) as well as the duration of each injection step. These model results can subsequently be downloaded to Level 1.

The Precalculation Model is started automatically at take-over of the heat and at defined process events (e.g. temperature measurement, new hot metal sample received, aim sulphur content changed). Additionally, this calculation can be started manually during the treatment on operator's request.

Mono-injection as well as co-injection desulphurisation practices are supported by the model. The injection schemes can be defined by the process engineer in the Level 2 database. The Precalculation Model uses these injection schemes as input for simulating the heat and calculating the injection material setpoints.

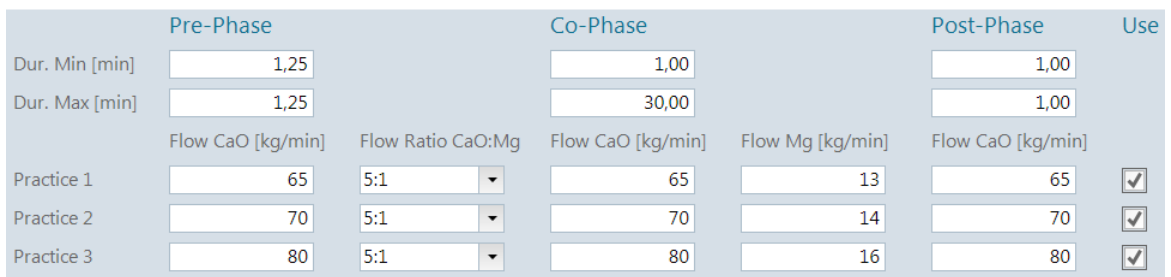

Figure 3. Typical Co-Injection Scheme (with Injection Ratio $\mathrm{CaO}: \mathrm{Mg}=5: 1$ )

Here, Pre-Phase, Co-Phase and Post-Phase denote the different treatment steps of the co-injection scheme. Dur. Min/Max defines the minimal and maximal allowed durations of the treatment steps. The Precalculation Model uses flow rate practices (Practice 1, Practice 2 and Practice 3) for its calculations. The Use flag indicates whether a certain flow rate practice should be considered by the Precalculation Model or not.

The Precalculation Model will employ all possible treatment schemes (mono- and coinjection) which are currently in use for simulating the heat. The list of model results, that is, calculated treatment times, material amounts and material costs will be shown on the user interface. The optimal solution according the optimization mode (cost, time or cost by available time) will pre-selected, see the green line in Figure 4. From this list the operator can select the practice to be actually used in the desulphurisation treatment.

\begin{tabular}{|c|c|c|c|c|c|c|c|c|c|c|c|c|}
\hline \multicolumn{13}{|c|}{ DES Practice Selection } \\
\hline \multicolumn{3}{|c|}{ Calculation } & \multicolumn{2}{|c|}{ Materials Wt. [kg] } & \multirow[b]{2}{*}{ Price } & \multirow[b]{2}{*}{$\begin{array}{l}\text { S Tmt. } \\
\text { End } \\
{[\%]}\end{array}$} & \multicolumn{2}{|c|}{ Step 01} & \multicolumn{4}{|c|}{ Step 02} \\
\hline Type & Ratio & $\begin{array}{c}\text { Dur. } \\
{[\mathrm{mm}: \mathrm{ss}]}\end{array}$ & $\begin{array}{l}\text { CAD9F3 } \\
(\mathrm{CaC} 2)\end{array}$ & MgInj & & & $\begin{array}{c}\text { CAD9F3 } \\
(\mathrm{CaC2}) \\
\text { Wt. }\end{array}$ & $\begin{array}{c}\text { CAD9F3 } \\
\text { (CaC2) } \\
\text { Rt. }\end{array}$ & $\begin{array}{c}\text { CAD9F3 } \\
(\mathrm{CaC} 2) \\
\text { Wt. }\end{array}$ & $\begin{array}{c}\text { CAD9F3 } \\
\text { (CaC2) } \\
\text { Rt. }\end{array}$ & $\begin{array}{l}\text { MgInj } \\
\text { Wt. }\end{array}$ & $\begin{array}{l}\text { MgInj } \\
\text { Rt. }\end{array}$ \\
\hline Co & $8.3: 1$ & $10: 52$ & 450 & 47 & 18136 & 0,0098 & 38 & 50,0 & 388 & 50,0 & 47 & 6,0 \\
\hline Co & $5.0: 1$ & $11: 32$ & 387 & 67 & 15597 & 0,0098 & 30 & 40,0 & 337 & 40,0 & 67 & 8,0 \\
\hline Co & $11.9: 1$ & $11: 32$ & 483 & 36 & 19472 & 0,0098 & 25 & 50,0 & 433 & 50,0 & 36 & 4,2 \\
\hline Co & $11.8: 1$ & $12: 37$ & 484 & 37 & 19489 & 0,0098 & 23 & 45,0 & 439 & 45,0 & 37 & 3,8 \\
\hline Mono & - & $15: 07$ & 596 & & 23999 & 0,0100 & 596 & 45,0 & & & & \\
\hline
\end{tabular}

Figure 4. List of Precalculation Model Results.

The green line indicates the optimal result (for time optimization) pre-selected by the model. For each injection material, the availability, the price and the chemical analysis must be known. The process optimization mode has to be specified before take-over of the heat. The following optimization modes are supported:

- Cost Optimization: If cost optimization is specified, the Precalculation Model preselects the material cost-optimized model result to reach the aim sulphur content. Cost optimization may lead to an increased treatment time if, for instance, the cheapest material has a lower desulphurization efficiency. 
- Time Optimization: If time optimization is specified, the Precalculation Model preselects the most time-efficient (fastest) process route to reach the aim sulphur content. The "time optimization" is the default optimization mode.

\section{LADLE FURNACE}

The new Level 2 system has been implemented at the 3 ladle furnaces in meltshop SMS-I and the 4 ladle furnaces in SMS-II.

The automation system for the secondary metallurgical treatment station contains several process models. The purpose of these process models is the calculation and control of the state of the heat (weight of steel and slag and their temperature and composition) according to actual production conditions.

From a user point of view there are mainly two models:

- Precalculation Model: This model performs a simulation of the complete heat (starting from the current process step) and provides heating and material setpoints, which can be downloaded to Level 1 subsequently.

- Cyclic Online Model: Cyclic calculation of the status of heat (temperature, weight and analysis of steel and slag), taking into account chemical reactions and physical processes, as well as events like charging of materials and measurements.

The purpose of the precalculation is to ensure that the aim temperature and steel analysis at treatment end will be reached.

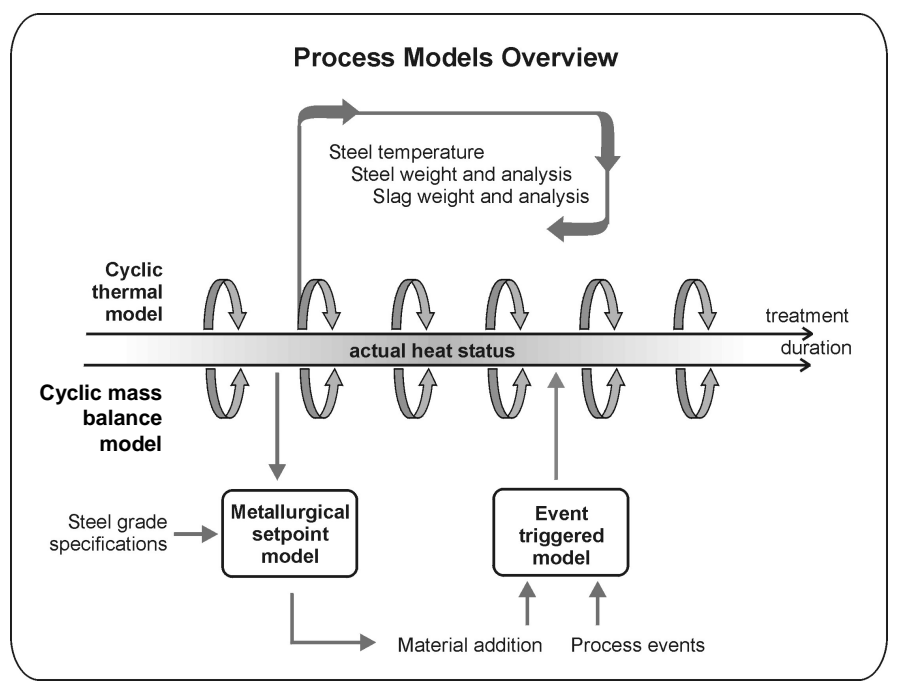

Figure 5. LF Process Models

The Precalculation Model is activated before heat start in order to perform a simulation of the complete LF treatment. Additionally this calculation can be started during treatment on operator's request or automatically after defined process events (e.g. temperature measurement, or aim temperature modified). It covers specific setpoint calculations for LF treatment such as temperature adjustment, alloying, deoxidation, desulphurization, slag conditioning and inclusion modification.

During the treatment the actual state of the heat is calculated by cyclically running all models over and over whilst updating them with actual process data. The result of this calculation can be observed in the trend viewer of the HMI online model application. The graphs in this viewer are not just drawn until the up to date time but also for the future of the current treatment. Hence, for each cyclic rerun of the models 
also an entire pre-calculation for the remaining treatment time has to be performed. Using that method the operator can conveniently observe the whole treatment visually based on a simulation incorporating all new incoming actual data.

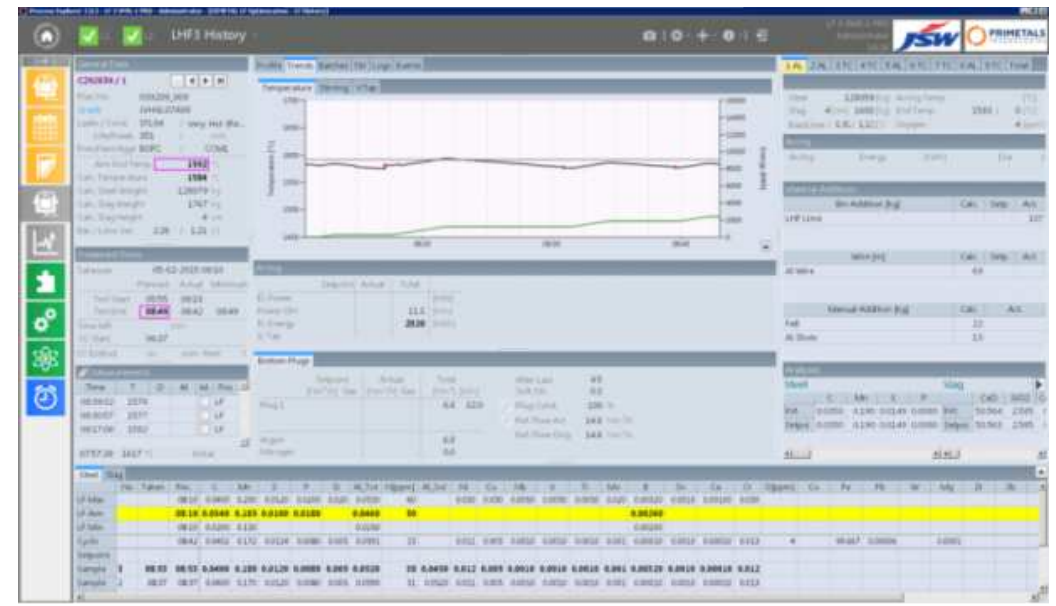

Figure 6. LF On-line HMI

\section{CONTINUOUS CASTING}

The new CC Level 2 system has also been implemented at the 4 continuous casting machines in meltshop SMS-I. A complete new installation has been done on Caster 1 \& 2 while Caster 3 \& 4 have been upgraded. Finally all Casters in SMS-I run the same CC Level 2 system version.

The basic functionality of the CC Level 2 system is production plan handling as heat and slab tracking from the first announcement of a heat until the last slab has left the caster run-out area. Production events as well as quality-related information are tracked by the system.

The following additional features and process models are built within the new Level 2 caster system at SMS-I:

- Heat Pacing: For sequence casting the steelmaking process is synchronized with the casting process

- Equipment Expert: Tracking and Maintenance of the main machine equipment and their components

- Dynacs Secondary Cooling System: Advanced process model for determination of the on-line temperature profile of the strand and calculation of the required water flow setpoints

- Nozzle Expert: Monitoring of the condition of the secondary cooling system

- DynaGap - Dynamic Gap Optimization: Advanced process model for optimum strand gap and soft reduction at the optimum position.

- Cut Length optimization: Application of optimization algorithms to cut as many prime length slabs as possible

- QE Quality Expert: Quality control for the slab casting (data tracking and quality evaluation).

- Caster simulator: The Caster Simulator is a script based test tool for the Caster Level 2 System. The utility implements a simulation system for important L1 Signals and events required for processing a heat at the caster. This simulation program is used to test new or modified functions. 


\section{SHOP SUPERVISORY FUNCTIONS}

The Shop Supervisory Function was implemented for both JSW melt shops at Toranagallu. The Shop Supervisory Function (SSF) is a web based application which gives complete overview of the plant starting from the hot metal output of Iron making unit to the final product at Caster. Main functionality of SSF is to gather information from different aggregates through external interface, different stations through operator input and display the information in an organized way online data and history data. Apart of this it has long term storage of historian data for reporting. Order information is displayed as received from Level-3 along with production status. Hot metal / Steel / Slag analysis result as received from different aggregates or from central laboratory is tracked heat wise and is displayed for online and history. Tracking of equipment based on number of heats or duration along with equipment master data are kept. Figure 7 shows an overview of the Shop Supervisory Function (SSF). This structure is a combination of SOA (Service Oriented Architecture) and NTier Architecture. The main difference between this and a client-server system is that the Web User Interfaces (HMIs) has no direct interaction with the database or with the Server tasks rather, it communicates through the Windows Communication Foundation (WCF) Service.

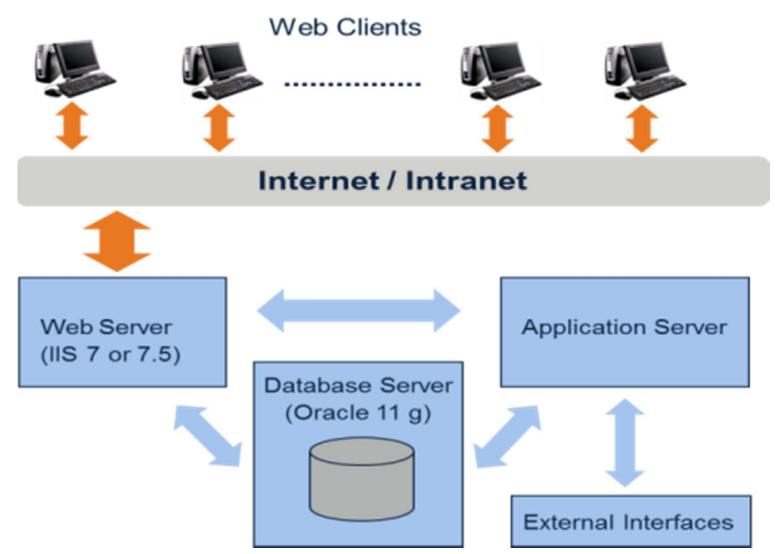

Figure 7. Shop Supervisory Function

The following applications are available in SSF Application (Process Web Explorer):

- Plant Overview - Live display of information for entire steel plant ( with detail aggregate type view)

- Plant Overview for Large Screen- Live display slide show of information for entire steel plant

- Prod. Schedule - Live display of production schedule information.

- Status Overview - Live display of information for Heats, Ladles

- Equipment Tracking - Tracking of equipments with status.

- Ladle Tracking Live tracking of the steel ladles at all the aggregates or ladle preparation area

- Analysis Viewer - Live display of analysis and display of historical analysis.

- Reports Viewer - Display of automatic generated reports and manual generation of reports in pdf and/or excel format

- Maintenance - Ladle \& Equipment maintenance

In the following the plant overview screens as well as the steel ladle tracking screen from the steel plant are shown. 


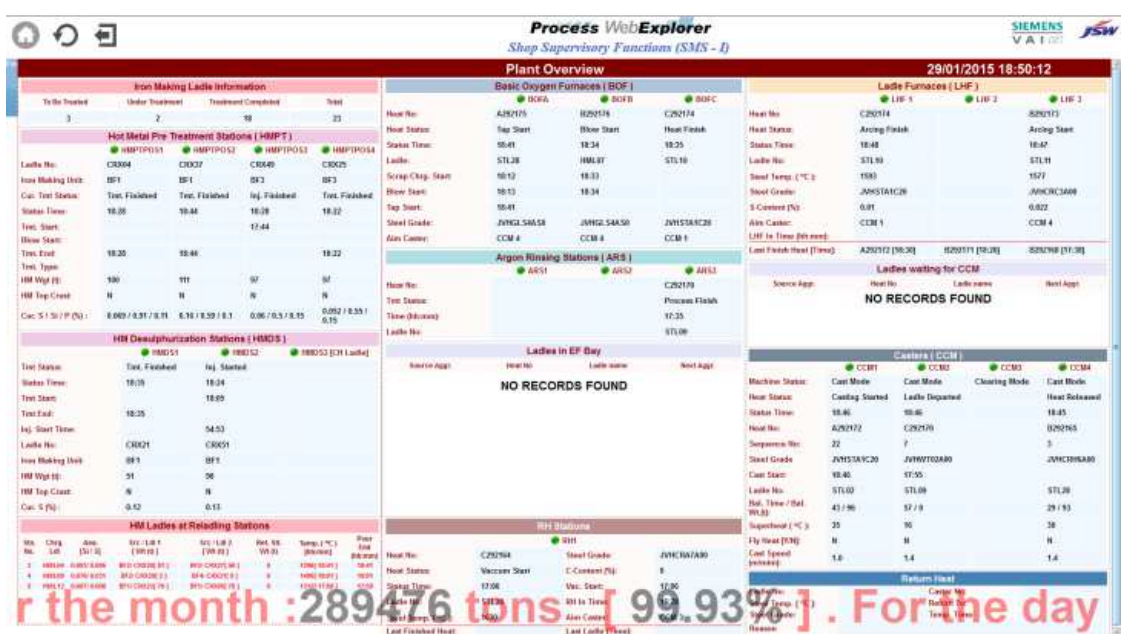

Figure 8. Plant overview screen SMS-I

\section{LADLE TRACKING}

The Ladle Tracking System (LTS) is a web based application which gives complete overview of the charging and steel ladles available in steel melt shop and handling of crane job. Based on the information gathered from external interfaces and operator input from crane and/or other areas, the system tracks the ladles and displays information in an organized way.

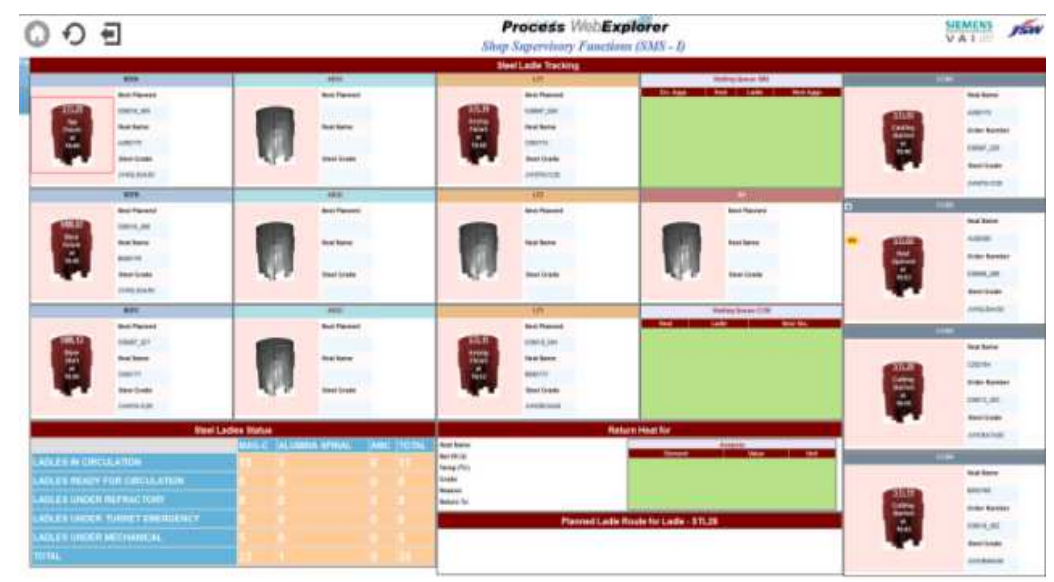

Figure 9. Steel Ladle Tracking SMS-I

The ladle information for each ladle campaign \& cycle is tracked and archived after end of cycle for review/report. Following are the highlights of the application

- Overview of all ladles with tracked properties and events

- Crane operation handling (Most of the crane job assigned automatically when ladle is in cycle)

- Auto job creation for crane based on received interface messages and other logic

- Crane job management for ground operator (based on actual situation in case of emergency/ out of cycle)

- Facility to assign charging ladle for converter along with route of ladle to have crane auto job

- Bay overview with available ladles and status, for crane and ground operator

- Ladle Inspection/Maintenance/Repair/Prepare activity handling

- Steel Ladle pouring operations (Partial/Full/distribution to multiple ladles etc.) 
- Thermal Ladle condition evaluation

- Tracking of Ladle life (campaign life, lining life, slagzone life, plug life etc.)

- No client installation required (thin client)

- Ladle history archival for reporting and viewing

- Crane job evaluation report

- Easy configuration of Ladle properties \& events

- Application Compatible with all modern web browser (IE,Chrome,Mozilla)

- Can be upgraded to a full automatic ladle tracking system (Radar/RF ID based).

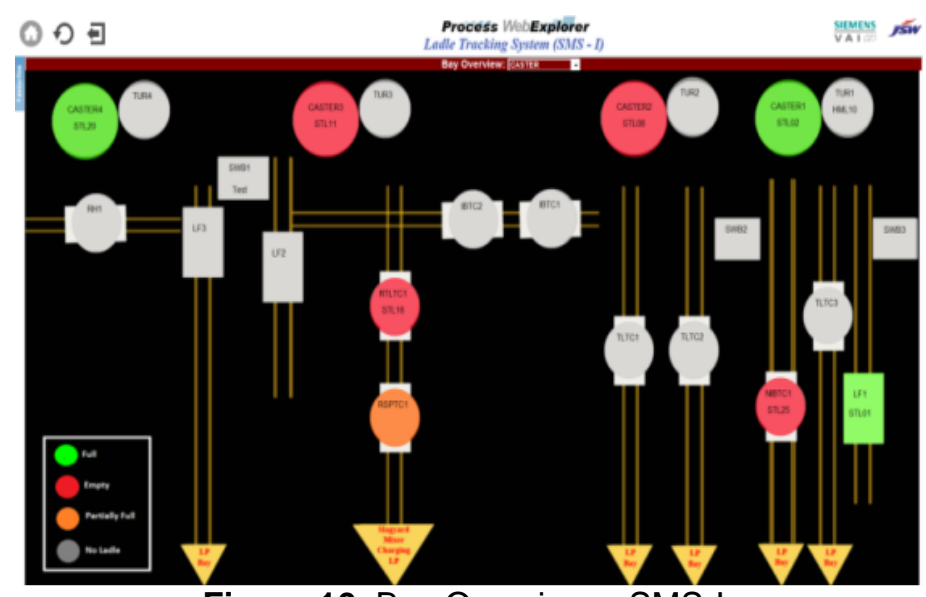

Figure 10. Bay Overview - SMS-I.

\section{CONCLUSION}

Primetals Technologies has implemented successfully new Level 2 process optimization systems for 25 plant units at JSW Toranagallu steel plant within the given time schedule. The Start-up of all available aggregates was completed as per schedule in 26 days. Our long lasting experience and the excellent cooperation with JSW have been the key factors for this success.

This major automation upgrade will support JSW in their strategy to stay on the leading edge of technical advancement and to further look for sustainable growth. 